NASA Technical Memorandum 100934

AIAA-88-3592

\title{
Effect of Initial Tangential Velocity Distribution on the Mean Evolution of a Swirling Turbulent Free Jet
}

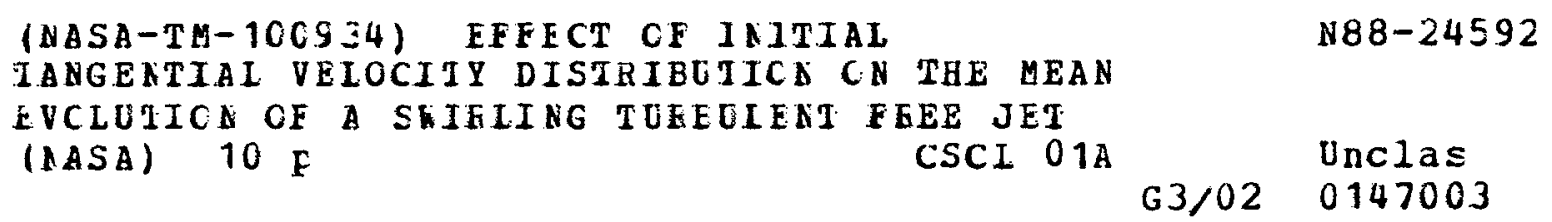
G3/02 0147003

N88-24592

Unclas

S. Farokhi and R. Taghavi

The University of Kansas

Lawrence, Kansas

and

E.J. Rice

Lewis Research Center

Cleveland, Ohio

Prepared for the

First National Fluid Dynamics Congress

sponsored by the ASME, AIAA, ASCE, SIAM, and APS

Cincinnati, Ohio, July 24-28, 1988 
EFFECT OF INITIAL TANGENTIAL VELOCITY DISTRIBUTION ON THE MEAN EVOLUTION OF A SWIRLING TURBULENT FREE JET

\author{
S. Farokh1 ${ }^{\star}$ \\ Aerospace Englneering Dept., The University of Kansas, Lawrence, Kansas \\ R. Taghavi** \\ Center for Research, Inc., The UnIversity of Kansas, Lawrence, Kansas \\ E. J. Rice \\ National Aeronautics and Space Administration, Lewis Research Center, Cleveland, Ohio
}

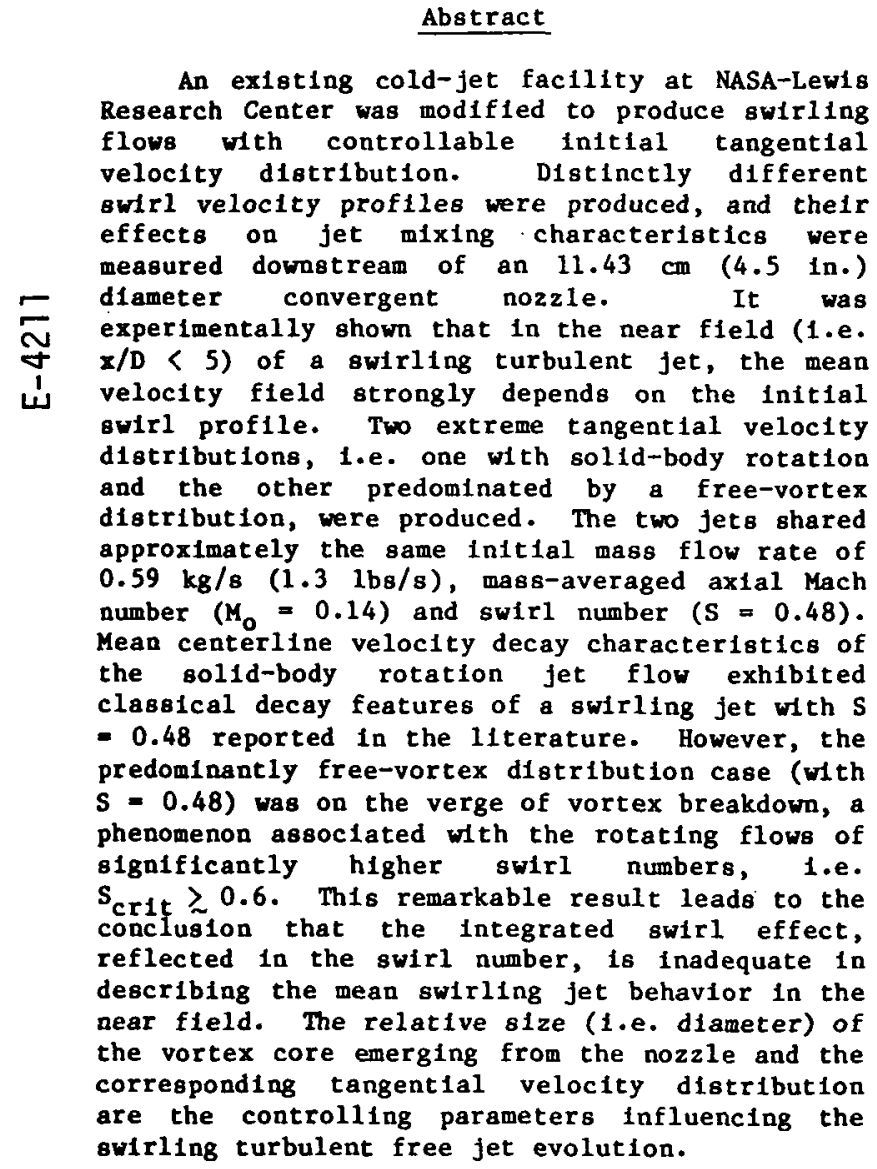

Nomenclature

$A, B, C$ outer, middle, and inner swir1generating manifolds, respectively

C constant

D nozzle exit diameter

G degree of swirl $\equiv w_{m o} / U$

$G_{x}$ axial flux of axial momentum

$G_{\theta}$ axial flux of angular momentum

M mean axial Mach number (based on the mass-averaged axial velocity)

O order of

p static pressure

\author{
$R$ nozzle exit radius \\ S swirl number $\equiv G_{\theta} / G_{R} R$ \\ $U, V, W$ mean axial, radial and tangential \\ velocity components in the jet \\ $u^{\prime}, v^{\prime}, w^{\prime}$ fluctuating axial, radial and \\ tangential velocity components in the \\ jet \\ $x, r, \theta$ cylindrical polar coordinates in the \\ jet \\ $\varepsilon$ very small quantity \\ $\rho$ fluid density
}

Subscript

crit critical

m. maximum

- Initial value, (i.e. condition at $x / D=$ 0.)

- unperturbed, ambient condition

$x$ quantity along the jet centerilne

\section{Introduction}

Turbulent jets with swirl exhibit distinctive characters absent in their nonrotating counterparts. A subsonic swirl-free jet, for example, experiences theoretically no static pressure gradient in the axial or radial direction. Hence, in this case, the mechanlsm for jet spread is dominated by the turbulent mixing at the interface between the jet and the ambient fluid. A turbulent jet with strong swirl, on the other hand, is primarily driven in the near field $(x / D<5)$ by the static pressure gradients in both axial and radial directions, i.e. mainly an inviscid phenomenon. Turbulent mixing then becomes a dominant factor only when the strong pressure gradients are weakened through rapid intial jet spread (1.e. a jet in near pressure equilibrium). The occurrence of flow reversal in the fet, or what is known as vortex breakdown is a fascinating phenomenon observed in high-intensity swirling flows, which we will briefly discuss in this paper. The absence of a potential core, by definition, in a swirling jet is another feature which distingulshes the rotating from the non-rotating jets.

The non-dimensional parameter describing the integrated swirl strength in a jet is the swirl number $S$, and is defined as

$$
S \equiv G_{\theta} / G_{x} R
$$

where $G_{\theta} \equiv 2 \pi \int_{0}^{\infty} \rho U \mathrm{Wr}^{2} \cdot \mathrm{dr}$; jet corque,

\footnotetext{
*Asboclate Professor
} 


$$
G_{x} \equiv 2 \pi \int_{0}^{\infty}\left(\rho U^{2}+\left(p-p_{\infty}\right)\right) r d r
$$

jet axial thrust,

and $R$ is the nozzle exit radius. The inclusion of the turbulent shear and normal stresses,

$\rho \overline{u^{\prime} w^{\prime}}$ and $\rho \overline{u^{\prime 2}}$, In the Integrands of the jet torque and thrust expressions, 1.e. equations (2) and (3) respectively provide for total jet thrust and torque as described in Reference [1]. However, our swirl number definition excludes Reynolds stresses. By definition, the swirl number 18 an integrated quantity, hence it is possible to generate swirling jets wh th different initial tangential velocity profiles ranging from solld body rotation ( $1 . e . W_{0}(r)=c . r$ ) to near free-vortex flow (i.e. $W_{0}(r) \approx c / r$ ) with constant S. Moreover, as the static pressure field is coupled to the tangentlal velocity distribution, through the momentum equations, and dominates the swirling fet evolution in the near field, vastly different mean jet behavior (e.g. mean centerline velocity decay) should be observable in swirling jets with constant $S$. To pursue this point further, a unique swirl generator was designed and incorporated in an existing cold fet facility at NASA-Lewls Research Center. The mean flow measurement technique employed five-hole pitot probes which compared favorably with the DCsignal of a hotwlre anemometer. The bigger objective of our Investigation 1s, however, to

a) study mixing characteristics of

b) evaluate excitability of (1.e. jet response to aerodynamic excitations) and

c) Investigate vortex breakdown in

swirling turbulent free fets with controllable infial tangential velocity distribution, from the incompressible limit to supersonic speeds. The present paper covers the mean, incompressible part of the task (a) while Reference [2] has addressed the swirling free jet excitabllity question and task (c) is currently under investigation.

\section{Review of Literature}

From a large body of experimental and theoretical works on the swirling turbulent flows only a few are selected for the purpose of review in this paper. The bulk of the swirl flow investigations may be categorized, with some interdependence, as follows:

a) swrling turbulent free jet issuing from an orifice into a stationary or moving fluid

b) confined swirling flows in varlablearea ducts (e.g. combustion aerodynamics)

c) swirling flow in turbomachinery annuli

d) vortex control and management in external/Internal aerodynamics

e) leading-edge vortex breakdown over a high-angle-of-at tack delta wing

The present review concentrates on swirling turbulent free jets with a brief look on the pertinent 11terature in related areas.

As might be expected, the evolution of a subsonic swirling turbulent jet issuing from a nozzle into ambient fluid depends on the method of swirl production. This fact was acknowledged by Chigler and Beer in Reference [3], Pratte and Keffer in Reference [4] and others. The design of swirl generators in practice today use the following principles of swirl production, namely a) adjustable vanes, b) tangential blowing on the wall of a pipe with axial through flow, c) spinning, fully-developed pipe flow emerging from a long rotating tube ( 100 diameters long) and d) flow through a rotating perforated plate, among others. References [1] and [5] can be consulted on the detalls of various swirl generator designs and thelr corresponding limitations and efficiencles.

A number of theoretical studies covering laminar, turbulent, weak and strong swirling jets have been carried out in the past. Cortler [6] performed analytical studies of an incompressible laminar jet in the limit of very weak swirl. In this limit, the radial pressure gradient may be ignored, f.e. $p=p(x)$ only; and moreover a linearlzation of the momentum equations in swirl velocity is admissible. Based on these and the boundary layer approximation of the Navier-Stokes equations, Gortler reduces the evolution of a weakly swirling laminar jet problem to an elgenvalue problem of an ordinary, second-order differential equation. Furthermore, upon finding a suitable transformation for the dependent and Independent vartables, the governing differential equation is transformed into a Legendre type, for which exact solutions are derived. By replacing the kinematic viscosity with an effective constant eddy viscostty, Görtler generallzes his theory to Include turbulent, weakly swirling free jets as well. A theory is proposed by stelger and Bloom [7] in which incompressible and compressible, axially symetric laminar free mixing, e.g. wakes and jets, with small, moderate and large swirl can be examined. The tangential and axtal velocity components and the stagnation enthalpy are assumed to have polynomlal profiles in the radial direction. The assumption of very small radial velocity allowed the use of boundary-layer type formulation in the analysis. The Karman integral method is then applied to the viscous layer, 1.e. the wake, of a rotating axisymmetric body with no comparison to experimental data. Shao-Lin Lee [8] has obtalned closed-form solutions for an axisymetric turbulent swirling jet using simflarity assumptions for the axial and the tangential velocities. The radial and axial velocities are linked via an entrainment assumption, after G. 1 . Taylor [9]. The theoretical predictions are compared to the experimental data of Rose [10], where close agreement, In the case of weak swirl, 1s demonstrated. The experimental data reported by Rose [10] were collected in a swirling turbulent jet issuing from a long rotating tube. Lee's assumptions of the Gaussian axtal velocity distribution and the corresponding simflar tangential velocity profile were directly deduced from Rose' experiment, where similarity conditions were observed for $x / D>1.5$.

Chigier and Chervinski $[11,12]$ have performed theoretical and experimental studies of turbulent swirling jets lssulng from a round orifice. They used boundary layer approximations and assumptions of similar profiles to integrate the equations of motion for 
incompressible turbulent flows. The simflarity assumption was experimentally demonstrated to hold in a owlring jet, for weak and moderate swrls, for $x / D>4$. For strongly swlrling flows, where the mean axial velocity distribution shows a central trough, or what is also known as a double hump profile, the similarity was not observed unt1l 10 diameters. For $x / D>10$, the location of the maximum mean axial velocity shifted back to the jet centerline, from which polnt the similarity was observed. The measured mean axtal velocity and static pressure profiles were described by Gaussian error curves and the mean tangential velocity profile was expressed in terms of third-order polynomlals. The emplrical constants in the data-fit expressions of Chigier and Chervinsky are functions of the degree of swirl in the jet defined as

$$
G \equiv \mathrm{w}_{\mathrm{mo}} / \mathrm{u}_{\mathrm{mo}}
$$

the ratio of maximum mean tangential-to-axial velocity at the nozzle exit.

Mattingly and Oates [13] performed an experimental 1nvestigation of the mean, Incompressible mixing process in confined coannular swirling flows. In this investigation, the swirl was present in the inner stream only, thereby leading to flow conditions unstable in the sense of Rayleigh, 1.e. Instabtlity ensulng from an outwardly decreasing angular momentum. Enhanced radial mixing was attributed to the Rayle1gh Instability.

The latest reviews in the fleld of confined owirling flows $[14,15]$, primarily with combustion, reveal an exteasive reference $118 \mathrm{t}$ and activities in this area of research. For a more comprehensive and recent work on the predictions and measurements of the swirling flows in combustor geometries, Reference [16] may be consulted.

Kerrebrock [17] has proposed a general theory for the small disturbance field in strongly swirling flows in turbomachine annuli. He concluded that small amplitude "shear" disturbances are not purely convected but rather propagate slowly in flows stable in the sense of Rayleigh and are unstable in flows approaching free vortex.

Extensive literature exists on the phenomenon of vortex breakdown or flow reversal and vortex instabllity in strongly swirling flows. References $[18,19$, and 20] are among the most fundamental. Despite significant strides, still no comprehensive theoretical description of the phenomena leading to vortex breakdown ex1sts. The various theoretical ldeas of hydrodynamic stability and finite transition to a subsequent state, analogous to hydraulic jump, are proposed which provide only partial insight 1ato this complex flow phenomenon. For an exhaustive list of references and critical evaluation of the proposed theories, References [21], [22], and [23] should be consulted. The special problem of the bursting of leading-edge vortices (e.g. over delta wings) is examined in References [24] and [25]. In a recent contribution (Reference [26]) ShI et al, have experimentally investigated the location and control of vortex breakdown over a delta wing of high sweep angle.

Common to all the previous methods of swirl generation in free jets and ducts, as described in the experimental swirl research articles, is the production of near solld body rotation flows. In the following section, design of a unique swirl generator system capable of producing variable initial swirl profiles employing the principles of combined tangential and axial atr is brlefly described.

\section{Experimental Facility}

\section{Swlrl Generator}

Figure 1 is a schematic diagram of the test set-up. An existing cold jet facility at NASA Lewis Research Center was modified to generate flows at a wide range of swirl numbers. The principle of combining axial and tangential streams is applied for swirl generation. Axial a1r 18 introduced through a $20.32 \mathrm{~cm}$ (8 in.) p1pe at the end of the plenum. Tangential air enters the plenum chamber through 54 elbow nozzles mounted on three concentric circular rings as shown in Figures 1 and 2. Spectally designed restrictors and screens are inserted tato the elbow nozzles to reduce the orifice notse generation. The nozzle exit plane 18 of mult1hole design which also contributes to the nozzles' low-nolse character. Swirl number can be adjusted by remote control valves which vary the proportion of axial to tangential alr. The flow leaving the swirl generator passes through a bellmouth and an excitation section before discharging to the test cell through an $11.43 \mathrm{~cm}$ (4.50 1n.) dlameter nozzle. For more detalls regarding the swirl generator and test facillty see Reference [5].

\section{Mean-Flow Measurements}

Three components of time-mean velocity as well as static and total pressures are measured by a 5-hole pitot probe having a diameter of $0.318 \mathrm{~cm}(0.125 \mathrm{ln}$.$) . The probe tip has a 45-$ degree cone angle and the pressure ports are located at the midspan of the conical surface. The 5-hole probe is self-nulling in the yaw angle, while the pitch angle, the time-mean velocity components and the pressures are computed from callbration curves. The callbration Mach number range for the 5-hole probe varled between 0.08 and 0.4 .

\section{Results and Discussion}

The experimental results presented in this section are time-averaged data gathered from two swirling jets generated separately by the manifolds $A$ and $C$. The swirl number in both jets was held constant at 0.48 and the mass-averaged, mean axial Mach number at the nozzle exit was 0.14. The Reynolds' number based on the mean axial velocity and the nozzle diameter was In both cases 375,000 . Figure 3 is a defintion sketch showing the coordinates and the mean velocity components in the jet.

The two extreme tangential velocity distributions investigated in our facility are 


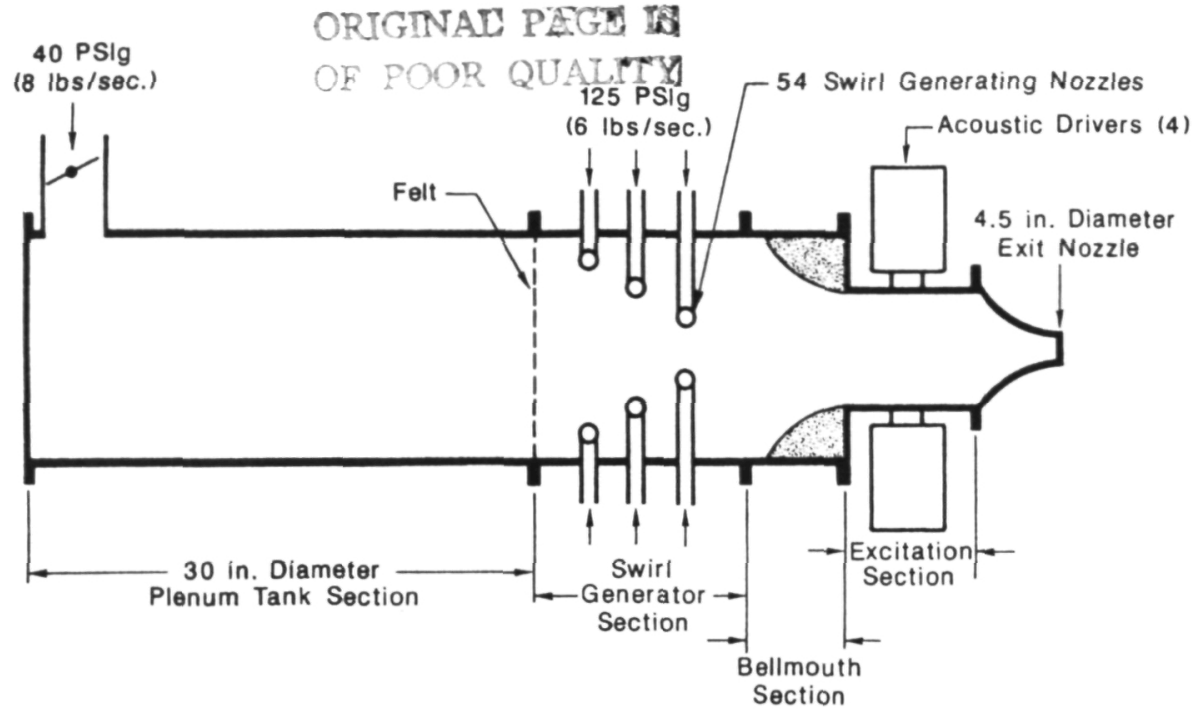

Figure 1. Schematic diagram of the jet facility

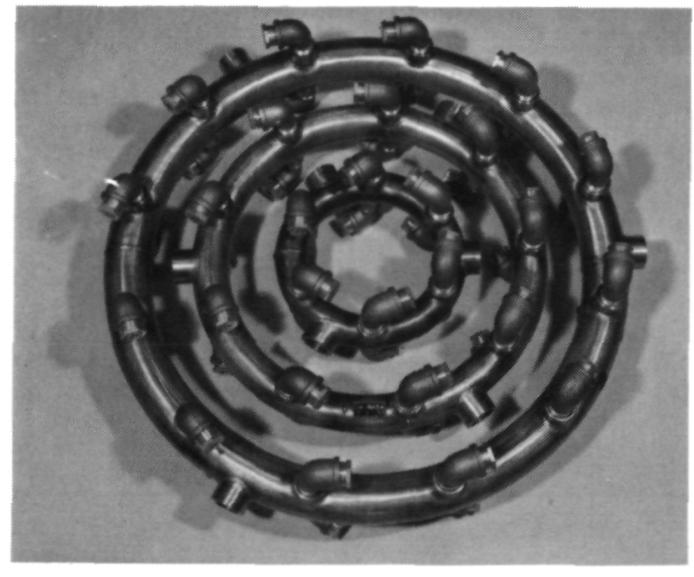

P1gure 2. Manifold rings and elbow nozzles (unassembled)

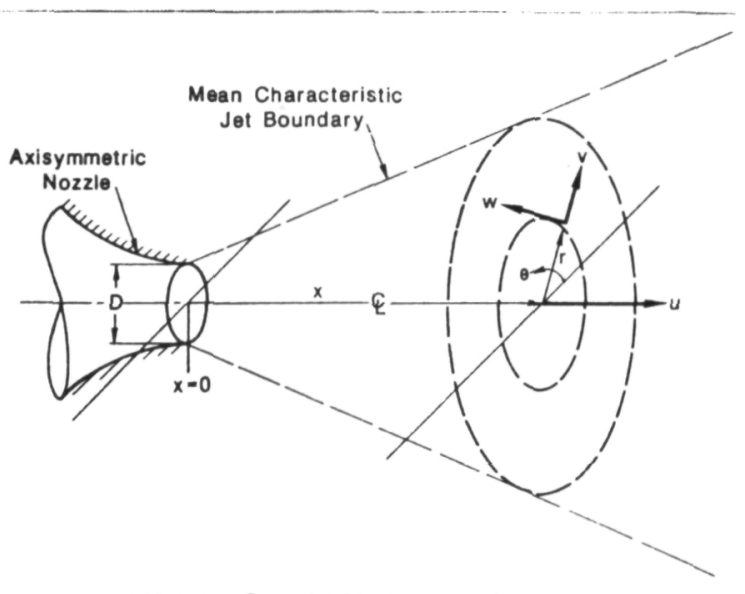

Pigure 3. Definition sketch

plotted in Figure 4. The vortex core size generated by the manifold $C$, at $x / D=0.06$, is about a quarter of the nozzle exit diameter; while that of the manifold A spans across the

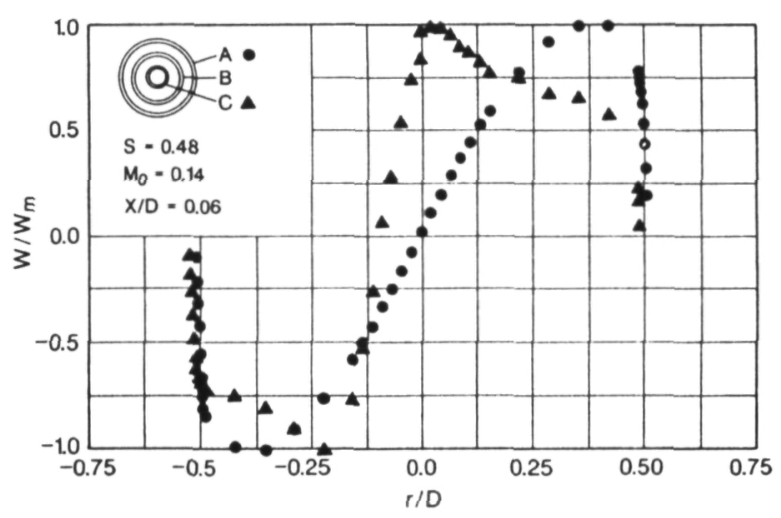

Figure 4. Radial distribution of the mean tangential velocity

full exit plane. It is also noted that the center of the smaller vortex is displaced from the nozzle geometric center by nearly $0.1 \mathrm{D}$, at $x / D=0.06$, thereby leading to non-axisymmetric flow conditions. This puzzling behavior was further Investigated by allowing the vortical flow to emerge from the nozzles of various lengths. It was noted that the vortex core center described a "helical path" as evidenced by the appearance of the vortex center above, below and to the side of the nozzle axis. A plausible explanation of this behavior may be found in the inviscid flow theory (see for example, Batchelor, Reference [27]) which predicts a spiral motion for an off-centered vortex filament as 1t passes through a contraction. The condition of axisymmetry for the swirling jet generated by the manifold $C$ is achieved at $x / D \approx 1.0$, as will be discussed later in this section. The forced vortex, 1.e. the solid body rotation flow, produced by the manifold $A$ is axisymmetric as it emerges from the nozzle.

The radial distribution of mean axial velocity is shown in Figure 5. It is the nature of vortical flows, in general, which would not 


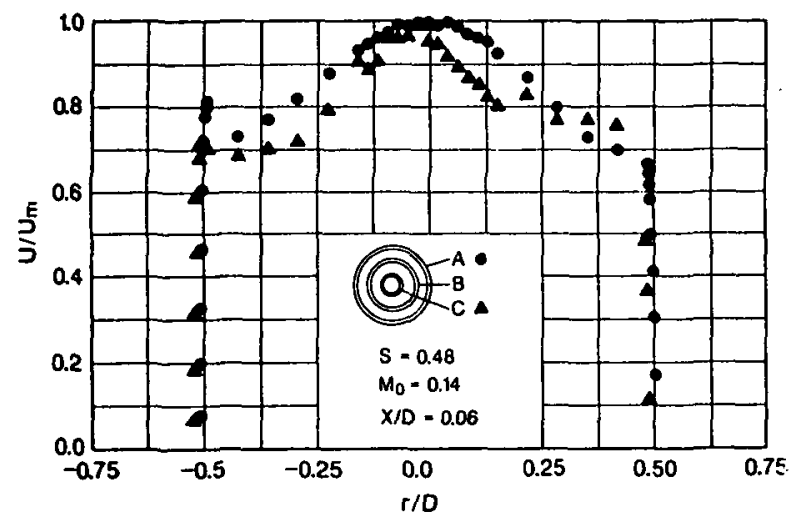

P1gure 5. Radial distribution of the mean axial velocity

allow flat top axial velocity profiles to be generated. The differences in the axial flow distributions at the nozzle exit produced by the mantfolds $A$ and $C$, as shown In Figure 5, could be directly related to the size of the vortex cores generated by these manifolds. Furthermore, the condition of near axisymmetry is observed for the swirling jet generated by the manifold $A$, while that of manifold $C$ is still asymetric.

An evidence of a very strong inward (1.e. negative) radial flow is revealed in Figure 6 for the manifold-C-generated swirling flow. Further, the magnttude of the radial and axial velocity components are comparable in this case in the near fleld. Hence, widely accepted boundary layer-type approximation, 1.e. $V / U \sim O(\varepsilon)$, made in the theoretical analysis of rotating jets 18 Invalid in the near field of even moderately swirling jets (e.g. with $S=0.48$ ). A manifestation of this assumption, i.e. $V / U \sim O(\varepsilon)$, on the radial momentum equation leads to the radial equilibrium condition, $1 . e$.

$$
-\frac{1}{p} \frac{\partial p}{\partial r}=\frac{v^{2}}{r}
$$

which is also invalid for the rotating free jets of the type generated by the manifold $C$ and deplcted in Figure 6. The driving force behind ouch a large radial inflow to the radial static pressure gradient associated with the core of such concentrated vortex fllaments identifying this as a pressure-driven phenomenon. The axial velocity peak observed in the jet center (see Pig. 5) Is the continulty-consequence of this radial Inflow. The flow generated by the largest manlfold, 1.e. A, experiences mild radial inflow and is axisymmetric. The rotating flow produced by the mallest manifold, 1.e. C, 18 asymmetric and, as shown in the latter parts of this section, w11 remain asymmetric up to $x / D=1$.

Figure 7 reveals a static pressure deficit In the core of the swirling jets, produced by the manifolds $A$ and $C$, at $x / D \approx 0.06$. The depth of the pressure trough for the concentrated vortex flow, 1.e. the one generated by the mantfold $C$, 18 nearly 2.5 times that of the large core vortex, 1.e. due to manifold $A$. We also note the similarity between the radial velocity and the static pressure profiles as plotted in Figures 6

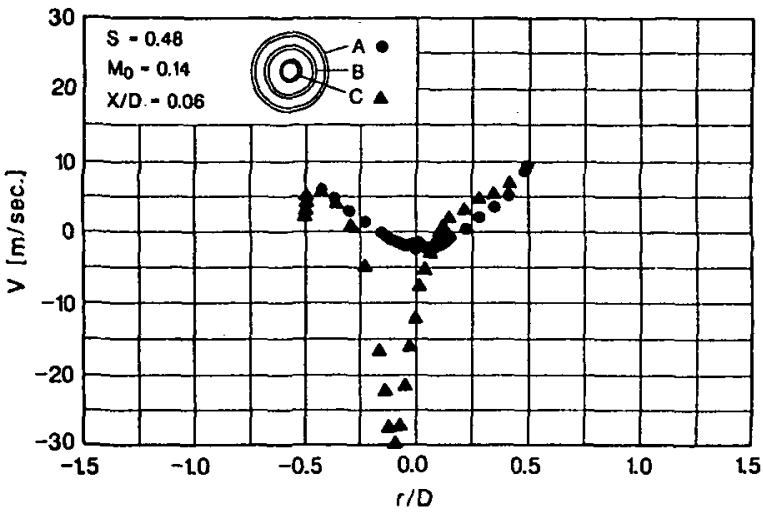

F1gure 6. Radial distribution of the mean radial veloc1ty

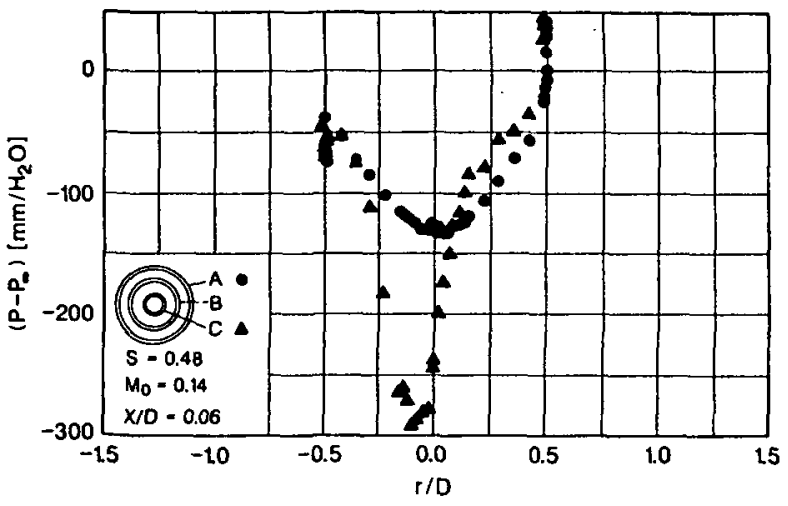

Figure 7. Radial distribution of the mean static pressure deficit

and 7. Again, the symmetry and lack of it could be seen in the $A$ and C-generated flows, respectively.

The axial evolution of the mean tangential velocity is plotted in Figure 8 (a) and (b). In part (a), the manifold A-generated swirling flow is clearly axisymmetric and shows a rapid decay wth axial distance. Beyond four diameters, the mean tangential velocity in the jet is so small as to make an accurate measurement with the 5hole probes questionable. The inftial offset between the jet and the nozzle geometric center is clearly visible, in Figure 8 (b), for $x / D<1.0$. Beyond one nozzle diameter, the two centers coincide. Moving towards the condition of axlsymmetry, 1.e. the self-centering action of the jet, is a natural tendency we observed in our experiments. Comparison of the parts (a) and (b) of Figure 8 also reveals that the concentrated vortex, 1 .e. due to manifold $C$, decays at a slower rate than the solid-body rotation flow induced by the manifold $A$, up to four nozzle diameter.

Widely different axial evolution of the mean axial velocity profiles, for the two swirling Jets generated by the manifolds $A$ and $C$, is noted from Figure 9 (a) and (b), respectively. The large core-vortex flow, 1.e. (a), shows a continuous gradual decay of the mean axial velocity 


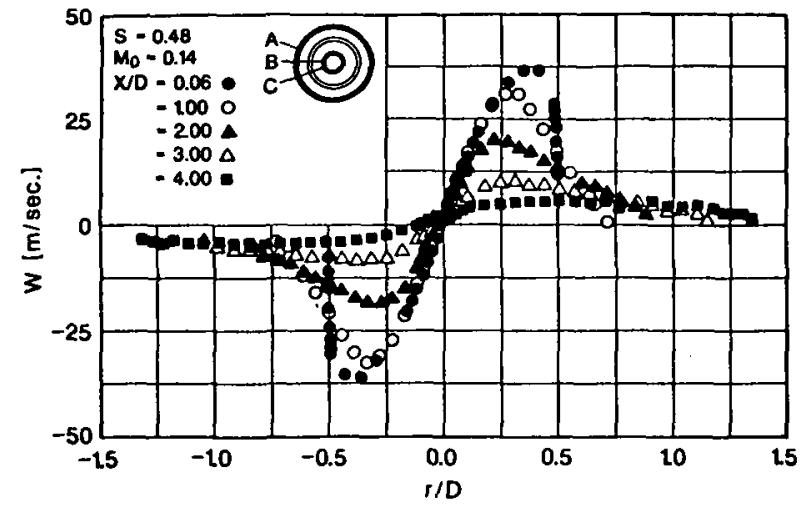

(a) Monifold $A$

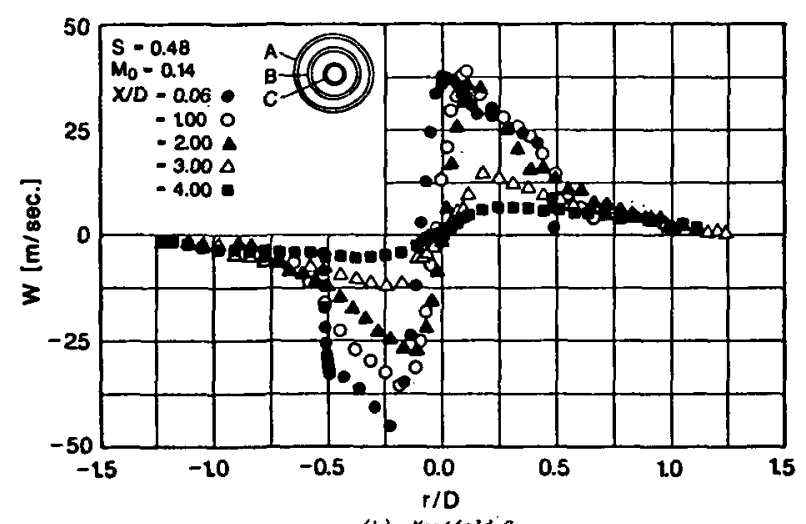

P1gure 8. Downstream development of the mean tangential velocity

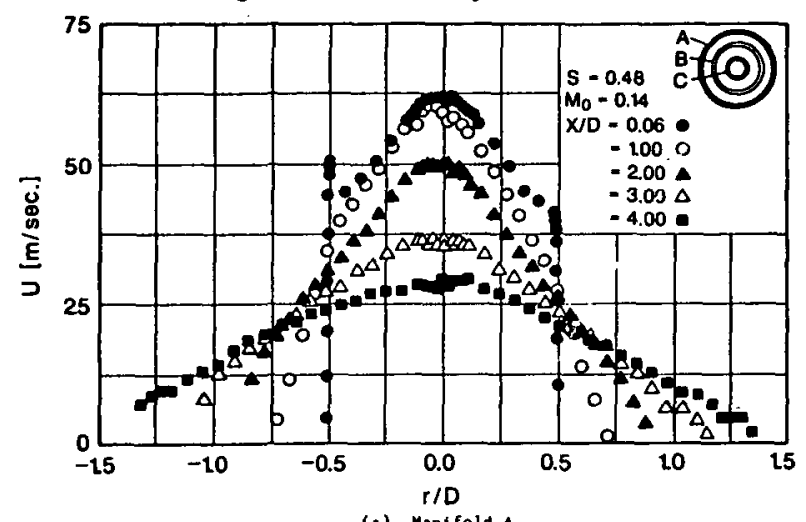

(a) Manifold A

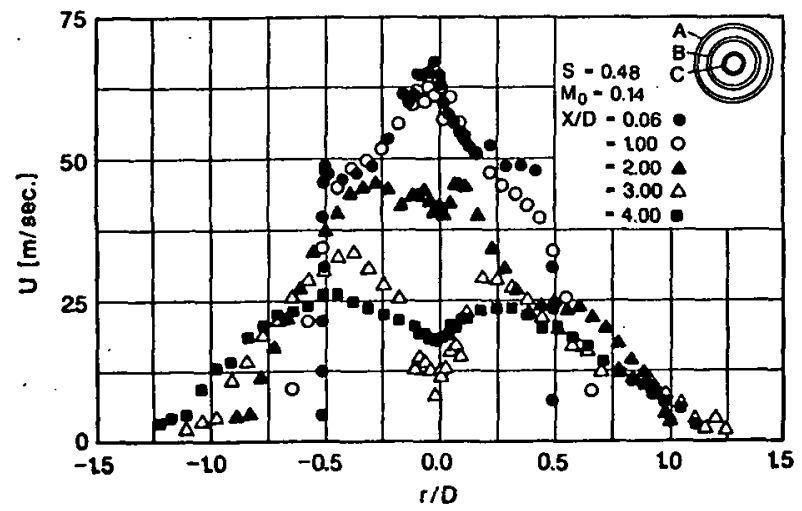

(b) Menifold $C$

F1gure 9. Downstream development of the mean axial velocity component along the jet. The small core-vortex flow, 1.e. (b), demonstrates a central trough or a double-hump profile associated with the swirl numbers higher than 0.48 (namely 0.6 ). The mean centerline velocity on the jet axis, 1.e. r/D = 0 , In part (b) shows a rapid inttlai deceleration followed by an acceleration period which has never been reported for $S=0.48$ jets. Upon further examination of the mean axial velocity between three and four diameters, we observed that the sma11-core-vortex jet with $S=0.48$ was on the verge of vortex breakdown, as shown in Figure 10. The forward and rear stagnation points, both very close to the fet axis, exhibited an unsteady behavior, as had been noted in the earlier vortex breakdown experiments. The fact that a swirling fet has been brought to the polnt of breakdown at a swirl number (1.e. 0.48) olgnificantly lower than the critical value was assumed to be (1.e. $S_{\text {crtt }} \geq 0.6$ ) is the wost remarkable result of our mean-flow investigation.

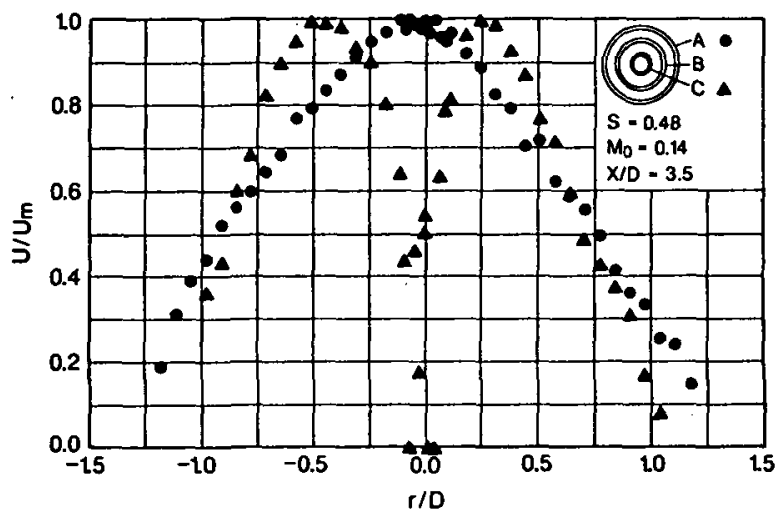

F1gure 10. Radial distribution of the mean axial velocity

Downstream development of the mean radial velocity is shown in Pigure 11. In part (a), a very minor radial inflow is measured which quickly disappears as the jet evolves in the axial direction. The small core-vortex flow, 1.e. (b), due to larger inflow radlal veloctties, persists longer than (a) and, as shown, decays to nearly zero radial velocity in about five diameters. The mean static pressure deficit in the sulring jet, within the first three diameters of the jet evolution is plotted in Pigure 12. The strong adverse pressure gradient along the fet axis, measured for the small corevortex flow, 1.e. part (b), is recognized as the principal contributor to the onset of the vortex breakdown as noted in figure 10 . Finally, the decay of the mean axial velocity along the jet axis is presented in Figure 13. The swirling jet produced by mantfold $C$ is on the verge of breakdown, while that of mantfold $A^{\prime}$ exhibits classical behavior for this level of swirl number, 1.e. 0.48 .

\section{Conclustons}

The following summarizes the major conclusions of our experimental investigation:

a. Initial development of a subsonic swirling free jet is dominated by the nozzle exit tangential velocity distribution. 


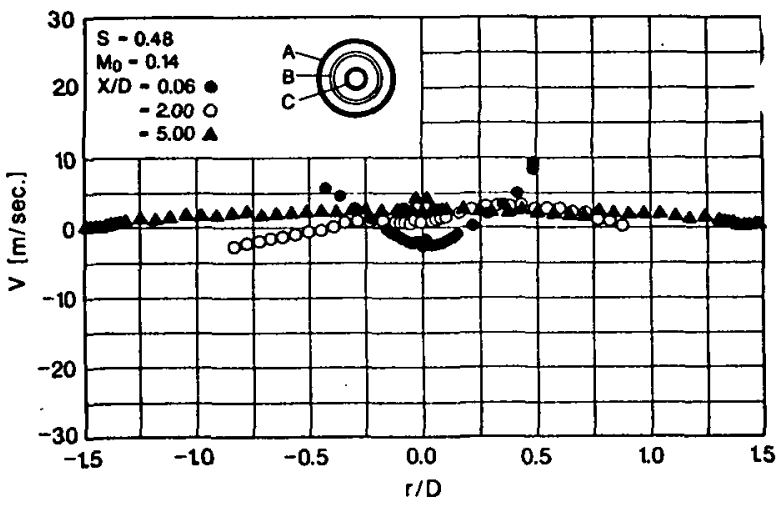

(a) Masifold $A$

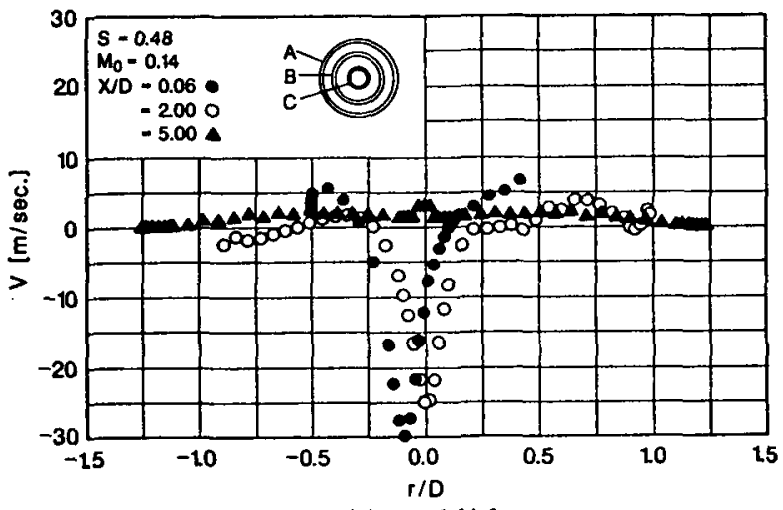

(b) Menifold $C$

Figure 11. Downst ream development of the mean radial velocity

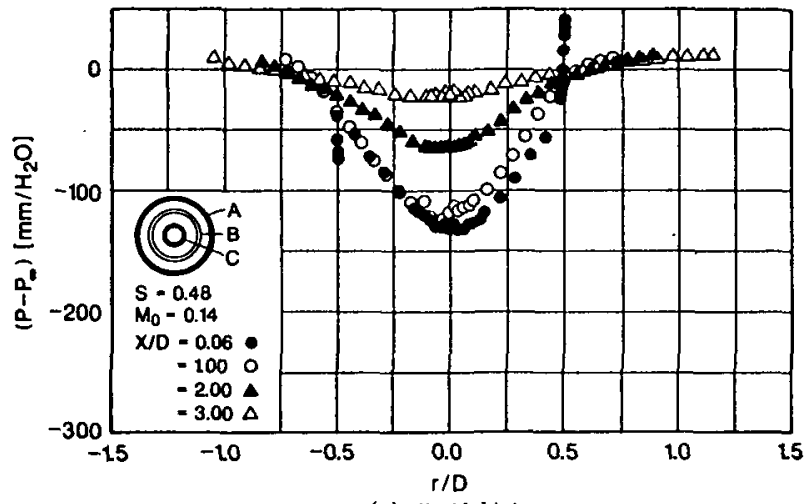

(a) Manifold $A$

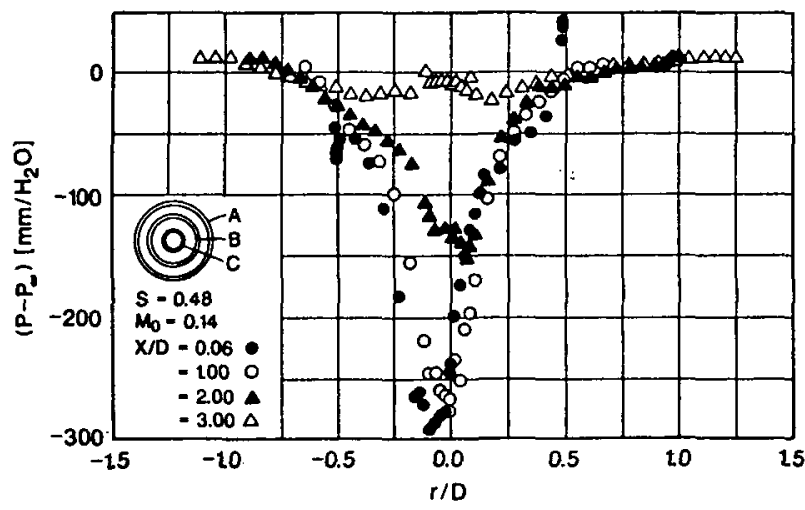

(b) Manifold $C$

Figure 12. Downstream development of the mean static pressure deficit

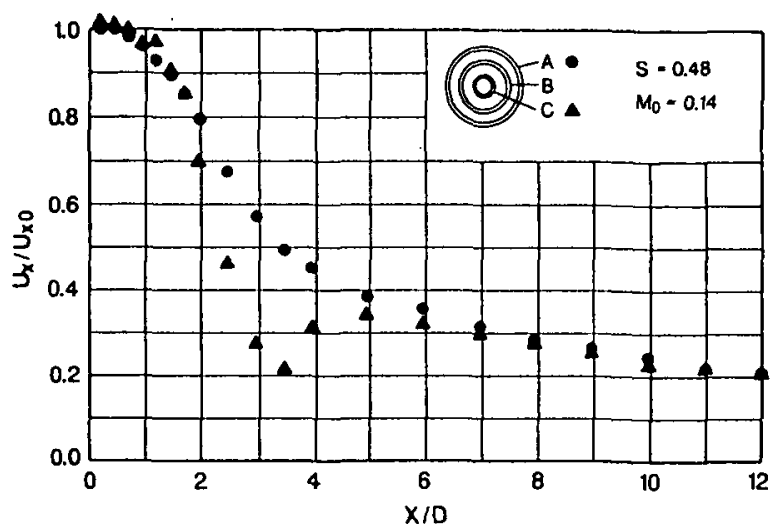

Figure 13. Decay of the mean axial veloctty component along the jet axis

b. Vortex breakdown in swirling jets may occur at significantly lower swirl numbers than have previously been reported, 1.e. $s_{\text {crtt }}<0.6$.

c. Large radial inflows will make a boundary-layer-type approximation, i.e. $V / U \sim O(\varepsilon)$, and 1 to subsequent radial equilibrium condition, invalid in the near field of the jets with moderate to strong swirls.

d. An asymmetric swirling free jet issuing from an axisymmetric nozzle will self center with distance (in our jet, within one nozzle diameter).

e. Reducing the size of. the vortex core in a swirling jet creates a higher swirlnumber effect on the mean flow.

\section{References}

1. Gupta, A.K., L1lley, D.G. and Syred, N., Swirl Flows, Abacus Press, Tuabridge Hells, England, 1984.

2. Taghav1, R., Rice, E.J. and Farokhi, S., "Controlled Excitation of a cold Turbulent Swirling Free Jet," Paper will be presented at the ASME Winter Annual Meeting in Boston, Massachusett8, Dec. 1987; W111 also appear in the Transactions of the ASME, Journal of Vibration, Acoustics, Stress and Reliability In Design.

3. Ch1gler, N.A. and Beér, J.M., "Veloclty and Static Pressure Distributions in Swirling A1r Jets Issulnğ from Annular and Divergent Nozzles," Transactions of the ASME, Journal of Basic Englneering, Dec. 1964, pp. 788796.

4. Pratte, B.D. and Keffer, J.F., The Swirling Turbulent Jet," Transactions of the ASME, Journal of Basic Englneering, Vol. 93, Dec. 1972, pp. 639-748.

5. Taghav1, R., "Experimental Invest1gation of Swirling "Turbulent Jets," Doctoral D1ssertation, the University of Kansas, Dct. 1987 . 
6. Gortler, H., "Decay of Swirl in an Axlally Symmetrical Jet, Far from the Orifice," Revista, Matemática Hispanoaméricas, Vol. 14, 1954, PP. 143-178.

7. Ste1ger, M.H. and Bloom, M.H., "Axlally Symmetric Laminar Free Mixing with Large Swlr1,: Transactions of the ASME, Journal of Heat Transfer, Vol. 84-85, Nov. 1962, PP. 370-374.

8. Lee, S.L., "Axisymmetrical Turbulent Swirling Jet," Transactions of the ASME, Journal of Applied Mechanics, Vo1. 32, 1965, pp. 258-262.

9. Taylor, G.I., "Dynamics of a Mass of Hot Gas Rising in Afr," U.S. Atomic Energy Comm18s1on, MDDC-919, LADC-276, 1945.

10. Rose, W.G., "A Swirling Round Turbulent Jet, Part 1: Mean Flow Measurements," Transactions of the ASME, Journal of Applled Mechan1C8, Dec. 1962, Pp. 615-625.

11. Chigler, N.A. and Chervinsky, A., "Experimental Investigation of Swirling Vortex Motion in Jets," Transactions of the ASME, Journal of Applied Mechanics, June 1967, Pp. 443-445.

12. Chigier, N.A. and Chervinsky, A., "Experimental and Theoretical Study of Turbulent Swirling Jets Issuing from a Round Orifice," Israel Journal of Technology, Vol. 4, No. 1, 1966, Pp. 44-54.

13. Mattingly, J.D. and Oates, G.C., "an Experimental Investigation of the Mixing of Coannular Swirling Flows," AIAA Journal. Vo1. 24, No. 5, May 1986, pp. 785-792.

14. Syred, N. and Beer, J:M., "Combustion in Swirling Flows: A Review," Combustion and Flame, Vol. 23, 1974, pp. 143-201.

15. L11ley, D.G., "Swirl Flows in Combustion: A Review," AIAA Journal, August 1977, pp. 1063-1078.

16. Rhode, D.L. and Lilley, D.G., Predictions and Measurements of Isothermal Flowfields in Ax1symetric Combustor Geometries, NASA CR174916, May 1985 .

17. Kerrebrock, J.L., "Small Disturbances in Turbomachine Annuli with Swirl," AIAA Journal, Vol. 15, No. 6, June 1977, pp. 794803.

18. Benjamin, T.B., "Theory of the Vortex Breakdown Phenomenon," Journal of Fluld Mechan1c8, Vol. 14, 1962, pp. 593-629.

19. Sarpkaya, T., "On Stat lonary and Travelling Vortex Breakdown," Journal of Fluld Mechanics, Vol. 45, 1971, Pp. 545-559.

20. Squire, H.B., "Analysis of the Vortex Breakdown Phenomenon," Miszellaneen der Angewandten Mechanik, Berlin, AkademieVerlag, 1960, pp. 306-312.

21. Hall, M.G., "Vortex Breakdown," Annual Review of Fluid Mechanics, Vol. 4, 1972, pp. 195-218.

22. Leibovich, S., "The Structure of Vortex Breakdown," Annual Review of Fluid Mechanic8, Vol. 10, 1978, Pp. 221-246.

23. Lelbovich, S., "Vortex Stability and Breakdown: Survey and Extension," AIAA Journal, Vol. 22, No. 9, 1984, pp. 11921206.

24. Lambourne, N.C. and Bryer, D.W., "The Bursting of Leading Edge Vortices; Some Observations and Discussion of the Phenomenon," Aeronautical Research Counc11, R \& M 3282, 1961 .
25. Hall, M.G., "A Theory for the Core of a Leading-Edge Vortex," Journal of Fluld Mechan1c8, Vot. 11, 1961, Pp. 209-228.

26. Shi, Z., Wu, J.M. and Vakil1, A.D., "An Investigation of Leading-Edge Vortices on Delta Wings with Jet Blowing," AIAA Paper No. 87-0330, 1987.

27. Batchelor, G.K., An Introduction to Fluid Dynamics, Cambridge University Press, Cambridge-England, 1967, pp. 543-555. 


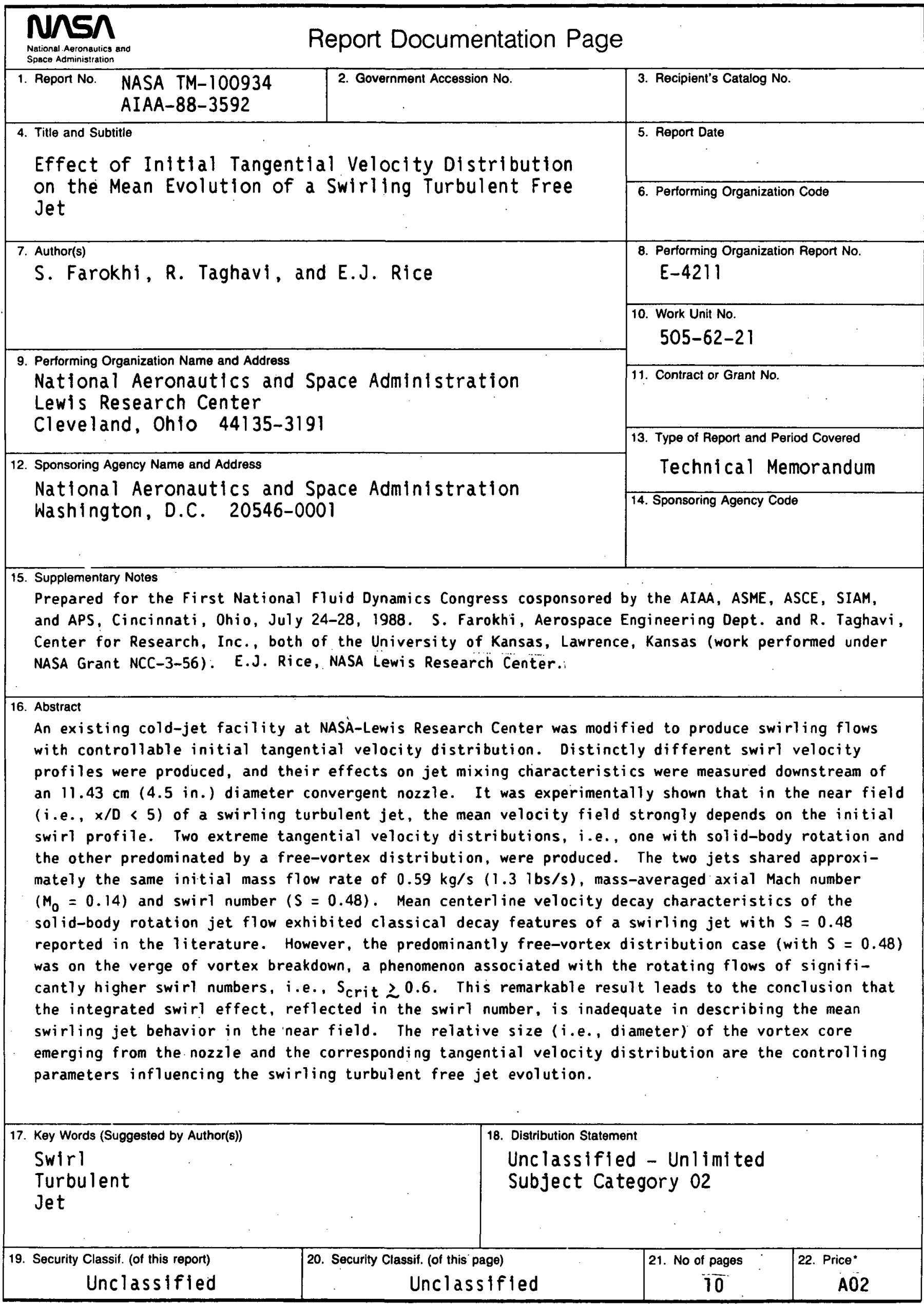


National Aeronautics and

Space Administration

Lewis Research Center

Cleveland, Ohio 44135

Oilicial Ausiness

Pentify for Prtvado Uee $\$ 300$
SECOND CLASS MAIL

ADDRESS CORRECTION REQUESTED

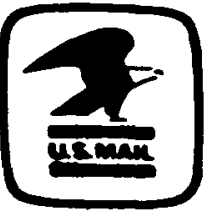

Postage and Fees Paid National Aeronautics and Space Administration NASA-451 